Some of these however are of limited value, and the narrative style while making for easy reading detracts from the didactic value for the specialist. While the book contains extensive historical references there is little new information for the ophthalmologist experienced in the field of retinal detachment, although it could be helpful background for residents.

I found it difficult to use the bibliography for reference to the text, and would have wished to see firmer recommendations and conclusions in the final chapter.

K. CALMET

Eye Movement Disorders. By A. J. GAY, N. M. Newman, J. L. Keltner, and M. N. Stroud. ig75. Pp. I56, figs, refs. Mosby, St Louis: Kimpton, London $(£ 8.70)$

This book seeks to provide physicians in the fields of ophthalmology, neurology, neuro-surgery, and otolaryngology with an understanding of supra-nuclear disorders of eye movements expressed in terms intelligible in the different specialties.

The preface informs us that the book is intended to be pragmatic. It provides first a conceptual framework for the understanding of supra-nuclear control of eye movements and a brief description of the pertinent neuroanatomy. Then it describes a methodical approach to the examination of eye movements with more detailed consideration of nystagmus and the vestibular motor system. Finally, the use of this approach in diagnosing eye movement disorders is outlined.

The authors have, without doubt, carried out their intention and although the presentation is perhaps an over simplification of the problems involved it is based on a wide knowledge of the literature and an extensive practical experience of the significance of disorders of ocular motility. The practical aspect is most apparent in the third chapter on examination of eye movements and the interpretation of the findings. There is certainly room for a textbook of this size in the library of any physician who meets and has to cope with the problems of eye movements. Its clinical and practical bias (even to the inclusion of a glossary) should recommend it to a wide readership.

S. J. H. MILLER

The Human Lens in Relation to Cataract. Giba Foundation Symposium 19 (new series). I973. Pp.324, figs, tables, refs. Elsevier, Amsterdam $(\$$ I6.70)
The Ciba Foundation symposia have always provided an excellent platform for detailed discussion on a given topic by workers trained in many different disciplines. The symposium on the human lens is a successful amalgam of these interests and provides both the clinician and research worker with an up-to-date account of the recent trends concerning cataract. This monograph in no way seeks to provide definitive answers, but points the way to where further advances are likely to occur. As the Chairman, Antoinette Pirie, points out, the very success of cataract extraction has diminished the interest and activity shown in fundamental research in the past. The various papers go some way to distinguish between nuclear and cortical cataracts, and an assessment is attempted of the nature and deposition of proteins. Similarly, the role of membranes and enzyme activities is also described. It is the practice of the Ciba Foundation to publish the discussions after the papers and this custom is continued here. Indeed, these embellish the text of the original paper with critical analysis. This book can be recommended without reservation to all ophthalmologists.

P. J. HOLMES SELLERS

Lecture Notes on Ophthalmology. $5^{\text {th }}$ ed., 1974 . By P. D. Trevor-Roper. I974. Pp. 125, figs. Blackwell, Oxford (£. .60$)$

The necessity for a fifth edition of this tiny book confirms its value to medical students to whom it can be strongly recommended.

BARRIE JAY

Science and Blindness: Retrospective and Prospective. Edited by M. D. Graham. I973. Pp. 21 2, figs. American Foundation for Blind Inc., New York (No price given)

This book comprises the collected papers and discussions from the 50th Anniversary Meeting of the American Foundation for the Blind.

It contains valuable material on the demography of blindness, psychosocial and educational research, the evaluation of visually impaired children, the preparation of visually impaired persons for the professions, and the interaction of research and social policy. There are also papers on prosthetics, blindness systems, sensory supplementation, and the market aspects of bio-medical research, The proceedings conclude with an international seminar. and there is a moving speech by the late Lord Fraser.

This volume can be highly recommended for workers in the field of blindness and its related problems.

REDMOND SMITH

\title{
Note
}

\section{Afro-Asian Congress of Ophthalmology}

\section{Madras, India, 4 to 8 January 1976}

The main subjects to be discussed include endemic eye diseases, corneal surgery and eye banks in developing countries, modern trends in the treatment of retinal detachment, recent advances in ocular therapeutics, and lesions of the visual pathway. Those interested may write to Dr J. Agarwal, Organizing Secretary, 29C Edward Elliots Road, Madras-4, India, for further particulars. 